\title{
Synthesis of Hexa-Allylamino-Cyclotriphosphazene as a Reactive Fire Retardant for Unsaturated Polyesters
}

\author{
Jenn-Fong Kuan, King-Fu Lin \\ Institute of Materials Science and Engineering, National Taiwan University, Taipei, Taiwan 10617, Republic of China
}

Received 19 August 2002; accepted 21 April 2003

\begin{abstract}
A phosphazene derivative, hexa-allylaminocyclotriphosphazene (HACTP), was synthesized through the aminolysis of hexa-chloro-cyclo-triphosphazene with excess allylamine. HACTP is a soluble light-brown crystalline solid, which melts at $90^{\circ} \mathrm{C}$. It was reactive after melt but decomposed at $236^{\circ} \mathrm{C}$. When it was incorporated into the resin formulations of unsaturated polyesters, it acted as a
\end{abstract}

reactive flame retardant. The oxygen index was increased from 20.5 to 25.2, rating from the flammable to self-distinguishable scale. (c) 2003 Wiley Periodicals, Inc. J Appl Polym Sci 91: 697-702, 2004

Key words: phosphazene; flame retardance; polyesters; resins; degradation

\section{INTRODUCTION}

Hexa-chloro-cyclotriphosphazene, $\left(\mathrm{NPCl}_{2}\right)_{3}$, has been synthesized by Rose since $1834 .{ }^{1}$ Up to now, extensive studies on its derivatives and applications are still active. $^{2-10}$ Their potential applications included solid polymer electrolytes, ${ }^{3,8}$ flame retardants, ${ }^{4,6}$ nonlinear optics, ${ }^{7}$ biodegradable materials, ${ }^{9,10}$ et al. In this study, we prepared the hexa-allylamino-cyclotriphosphazene (HACTP) by substituting the chloro groups of $\left(\mathrm{NPCl}_{2}\right)_{3}$ with allylamines and employed it as a reactive non-halogen flame retardant for unsaturated polyesters (UP).

The flame-retardant properties of phosphorus-containing compounds have been well documented. ${ }^{11-14}$ To explain briefly: they increased the char of polymers by esterification with the degraded residual. ${ }^{11,12}$ If they contain nitrogen atoms, they might produce nitrogen gas and ammonia, rendering the char intumescing to retard the flame propagation.

UP resins are based on a blend of phthalic anhydride and maleic anhydride esterified with propylene glycol. Phthalic anhydride and maleic anhydride provide vinyl groups for curing reactions with styrene, which not only acts as a chain extender after cure but also acts as a diluent before cure. When HACTP was added to the resin formulations, it could involve the curing reactions with its six vinyl groups. Therefore, in

\footnotetext{
Correspondence to: King-Fu Lin (kflin@ccms.ntu.edu.tw).

Contract grant sponsor: National Science Council in Taiwan, Republic of China; contract grant sponsor: NSC 862216-E002-011.
}

Journal of Applied Polymer Science, Vol. 91, 697-702 (2004) (C) 2003 Wiley Periodicals, Inc. this study, we investigated its reactivity and flame retardancy on the unsaturated polyesters.

\section{EXPERIMENTAL}

\section{Materials}

HACTP was synthesized through the aminolysis of $\left(\mathrm{NPCl}_{2}\right)_{3}$ with excess allylamine as follows: 0.3 mole $\left(\mathrm{NPCl}_{2}\right)_{3}$ (Strem Chemicals, Massachusetts) was dissolved to $700 \mathrm{~mL}$ chloroform in flask. Then, 3 mole allylamine (Lancaster, UK) was added dropwise to the flask with stir under dry nitrogen. After reacted at $50-60^{\circ} \mathrm{C}$ for $3-4$ days, the solution was added with $300 \mathrm{~mL}$ dichloromethane and washed with $200 \mathrm{~mL}$ distilled water for 2-3 times. The precipitated brown product was collected after the solvent was removed by vacuum. The final light-brown product of HACTP was recrystallized from cyclohexane with $71 \%$ yield.

A general-purpose unsaturated polyester resin (200AP, Eternal Chemical Co., Taiwan) was used for this study. Various amounts of HACTP in phr were dissolved in the UP resins first and then added with 3 phr benzoyl peroxide (BPO) as an initiator. Phr indicates parts per hundred parts of UP resin. After the ingredients were completely dissolved and became a clear solution, they were poured to the mold and cured in an air circulating oven at $70^{\circ} \mathrm{C}$ for $1 \mathrm{~h}$ plus $4 \mathrm{~h}$ at $150^{\circ} \mathrm{C}$ for postcure.

\section{Characterization}

${ }^{13} \mathrm{C}-\mathrm{NMR}$ and ${ }^{31} \mathrm{P}-\mathrm{NMR}$ (NMR: nuclear magnetic resonance) spectra were recorded on a Bruker AM300WB Model NMR spectrometer with deuterated chloroform $\left(\mathrm{CDCl}_{3}\right)$ as a solvent and tetramethylsilane 


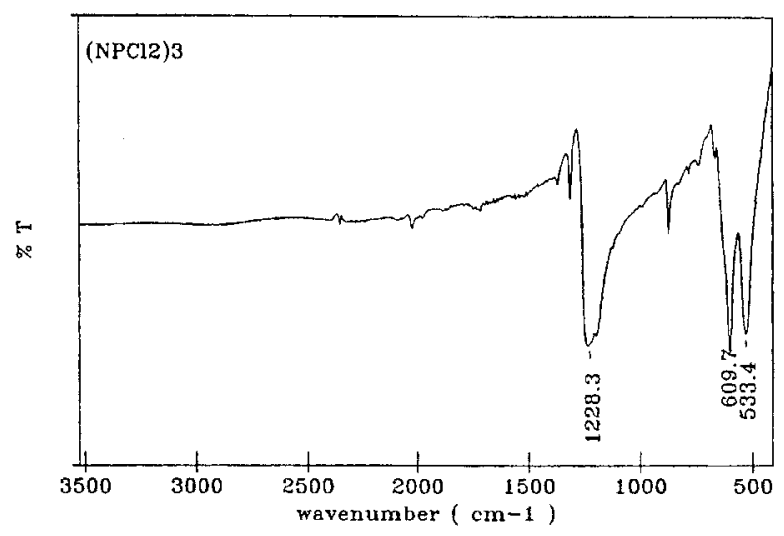

(a)

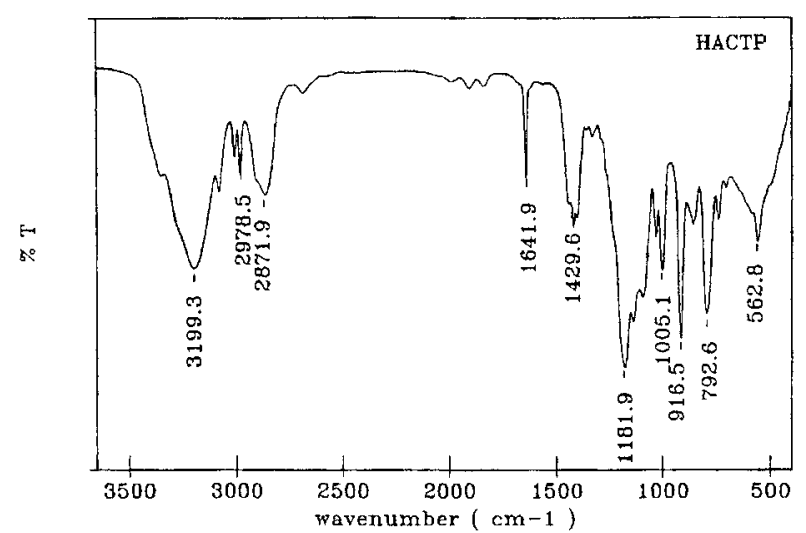

(b)

Figure 1 FTIR spectra of (a) $\left(\mathrm{NPCl}_{2}\right)_{3}$ and (b) HACTP.

as a standard. Infrared spectra were recorded on a Jasco 300E Model FTIR (Fourier transform infrared) with $\mathrm{KBr}$ pellets. Mass spectra were recorded on a Finnican TSQ-700 EI/MS Model mass spectrometer (EI/MS: electron ionization/mass spectroscopy). The specimens were introduced directly into the mass spectrometer and the pyrolysis was performed close to the ion source. The detail description of experimental procedure has been given elsewhere. ${ }^{15}$ Differential scanning calorimetry (DSC) was performed in a Du Pont 9900-910 Model DSC. Thermogravimetric analysis (TGA) was conducted in a 9900-954 Model TGA. Both thermal analyses were run in nitrogen atmosphere at a heating rate of $10^{\circ} \mathrm{C} \mathrm{min}^{-1}$. Elemental analysis was performed in a Perkin Elmer 2400 Model elemental analyzer. The minimum oxygen concentration as indicated by oxygen index to support the candle-like combustion of the specimens was measured according to ASTM D2863. The measurements were performed in a Polymer Lab HFTA II Model limit oxygen index meter.

\section{RESULTS AND DISCUSSION}

\section{Characterization of HACTP}

Figure 1 shows the FTIR spectra of $\left(\mathrm{NPCl}_{2}\right)_{3}$ and HACTP. The characteristic IR peaks of $\left(\mathrm{NPCl}_{2}\right)_{3}$ appeared at $1228 \mathrm{~cm}^{-1}$ for $\mathrm{N}=\mathrm{P}$ bonds and at 610 and $533 \mathrm{~cm}^{-1}$ for two $\mathrm{P}-\mathrm{Cl}$ bonds. When the chloro

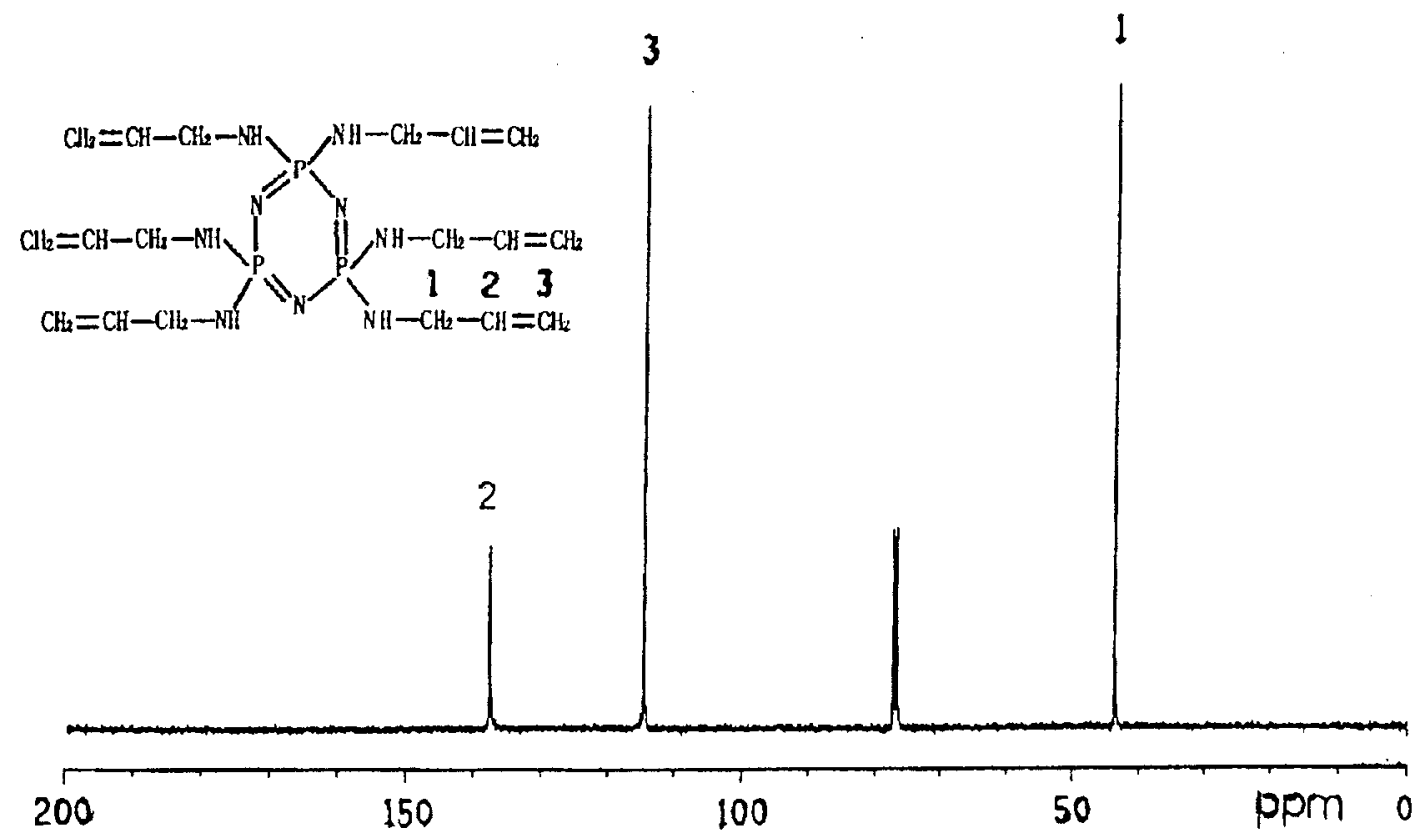

Figure $2{ }^{13} \mathrm{C}-\mathrm{NMR}$ spectrum of HACTP. 

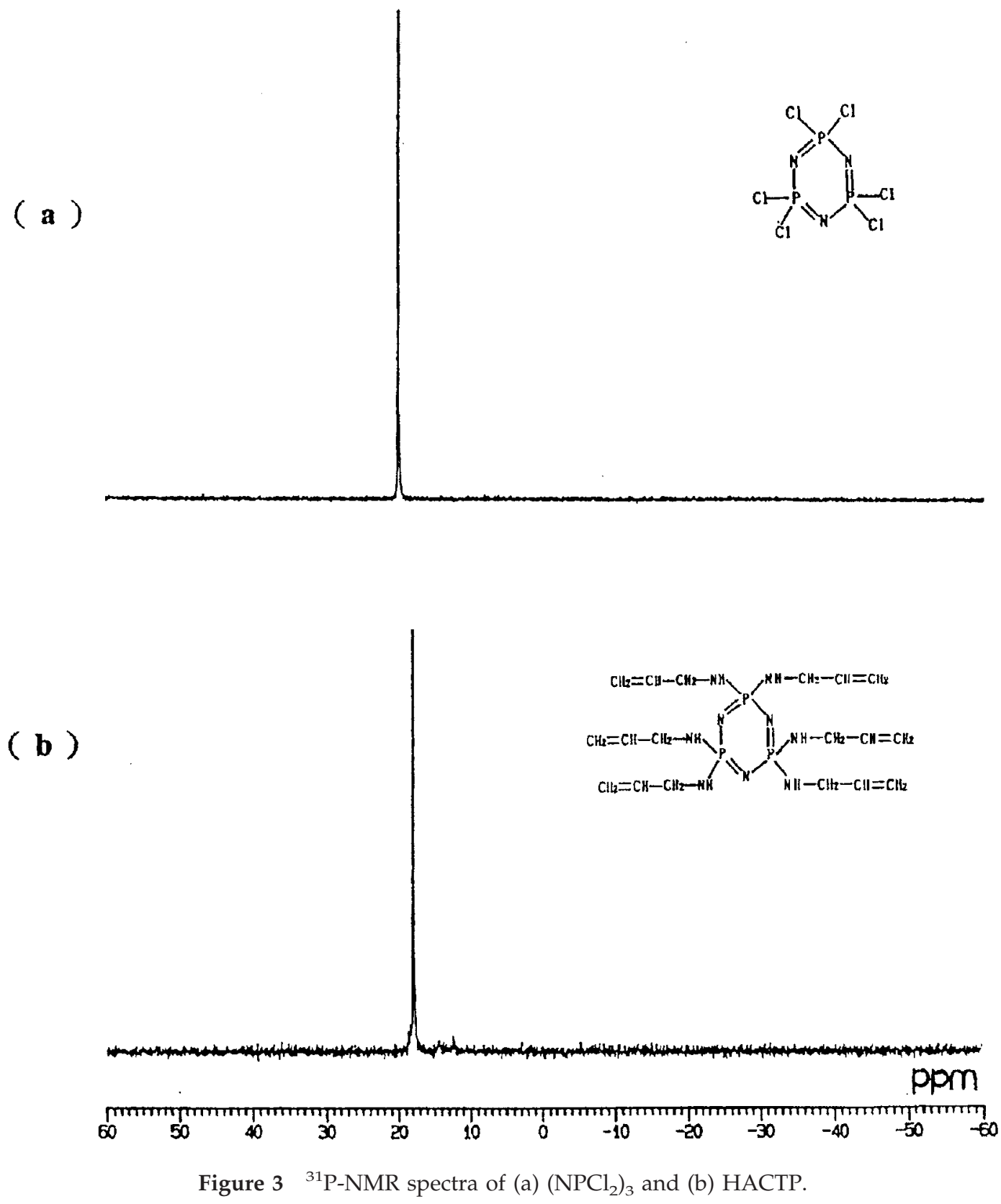

groups of $\left(\mathrm{NPCl}_{2}\right)_{3}$ were substituted with allylamines, the resulting HACTP has characteristic peaks appeared at $3199 \mathrm{~cm}^{-1}$ for $\mathrm{N}-\mathrm{H}$ groups, and at 1642 and $917 \mathrm{~cm}^{-1}$ for $\mathrm{C}=\mathrm{C}$ bonds. The IR peak of $\mathrm{P}=\mathrm{N}$ bonds were shifted to $1182 \mathrm{~cm}^{-1}$ as shown in Figure 1. The chemical structure of HACTP was further supported by ${ }^{13} \mathrm{C}-\mathrm{NMR}$ and ${ }^{31} \mathrm{P}-\mathrm{NMR}$ spectra (see Figs. 2 and 3). The ${ }^{13} \mathrm{C}-\mathrm{NMR}$ spectrum clearly shows three resonance peaks with their carbons assigned in Figure 2, whereas its ${ }^{31} \mathrm{P}-\mathrm{NMR}$ spectrum has only one peak appeared at $18.3 \mathrm{ppm}$. For comparison, the ${ }^{31} \mathrm{P}-\mathrm{NMR}$ spectrum of $\left(\mathrm{NPCl}_{2}\right)_{3}$ was also shown in Figure 3(a), whose sole resonance peak located at $20.1 \mathrm{ppm}$. The elemental analysis of HACTP found $\mathrm{C}=45.18 \%, \mathrm{H}=7.18 \%$, and $\mathrm{N}=26.28 \%$, very close to the calculated values of $\mathrm{C}=45.86 \%, \mathrm{H}=7.64 \%$, and $\mathrm{N}=26.75 \%$.
The molecular weight of HACTP determined from the mass spectrometry is 471 (see Fig. 4). Other significant observation on the mass spectrum of HACTP is its fragmentation to $m / e$ 430, 415, 375, 360, 320, 305, $263,248,206$, and 191. The major peaks at $m / e ~ 415,360$, 305,248 , and 191 are contributed by the sequential cleavages of allylamine groups from HACTP, whereas those at $m / e$ 430, 375, 320, 263, and 206 were contributed by the former fragments plus one $[-\mathrm{NH}]^{+}$ group. Similar cleavage of allylamines from the allylamine-adducted bismaleimide resins has been reported by our laboratory. ${ }^{15-17}$ The TGA data of HACTP shown in Figure 5 indicates a two-stage degradation behavior. By comparing to the mass spectrometry of HACTP, it is possible that the first stage of degradation at around $230-320^{\circ} \mathrm{C}$ was proceeded by 


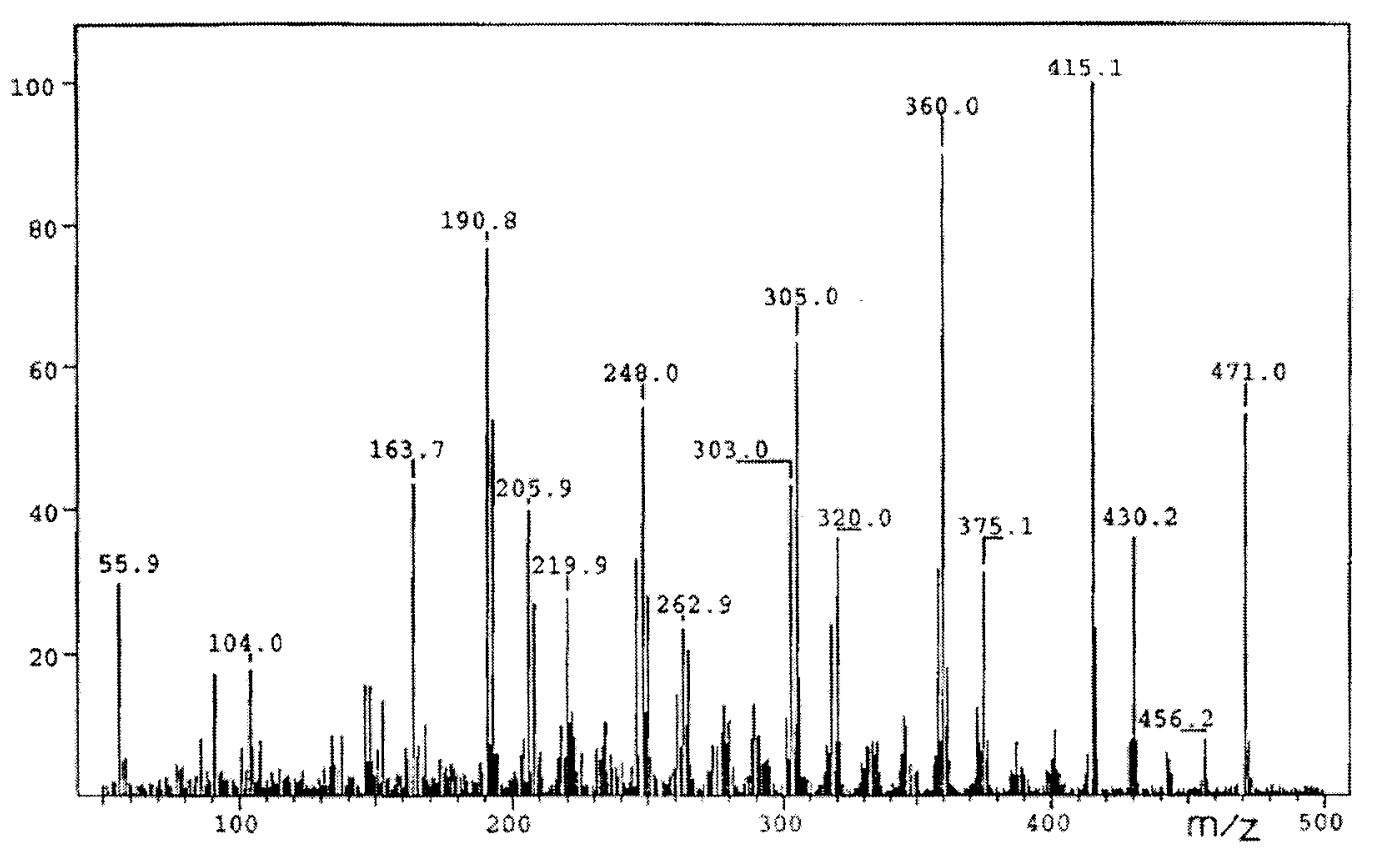

Figure 4 Mass spectrum of HACTP.

the cleavage of two allylamine groups remaining $\sim 76.5 \mathrm{wt} \%$ residue, and then proceeded with the cleavage of another two allylamine groups after $400^{\circ} \mathrm{C}$.

The DSC result shown in Figure 6 indicates that HACTP is a highly crystalline material with a melting temperature of $90.6^{\circ} \mathrm{C}$. It is mildly reactive after melt with the maximum reaction temperature at $168^{\circ} \mathrm{C}$.

\section{Curing reactions and flame retardancy of UP/HACTP resins}

HACTP can be dissolved to the UP resins up to $16 \mathrm{phr}$ and involve the curing reactions with its six allylamine groups. UP resins contain two kinds of double bonds for curing reactions. The one, indicated by the IR peak at $976 \mathrm{~cm}^{-1}$ [see Fig. 7(a)], is contributed by the phthalic anhydride and maleic anhydride joined in the main chains. Another with the IR peak appeared at $912 \mathrm{~cm}^{-1}$ is contributed by the styrene diluent. When the uncured UP resin was incorporated with HACTP, the intensity of IR peak at $912 \mathrm{~cm}^{-1}$ relative to that at $976 \mathrm{~cm}^{-1}$ was increased. The IR peak of secondary amino groups of HACTP also appeared at $3370 \mathrm{~cm}^{-1}$. Once those resins were cured, the IR peak at $975 \mathrm{~cm}^{-1}$ disappeared and that at $912 \mathrm{~cm}^{-1}$ was significantly reduced [see Fig. 7(b)]. Apparently, most of the double bonds were reacted except those of HACTP. HACTP involved curing reactions with its six double bonds but could not be completely reacted. DSC plots shown in Figure 8 indicate that the major curing reactions of UP resins occurred prior to the major reactions of HACTP. However, when the content of HACTP was higher than 8 phr, it could accelerate the curing reactions of UP resins (see Fig. 8). It is possible that the allylamine groups accelerated the initiation of $\mathrm{BPO}$ only when the concentration of HACTP was high enough for the HACTP molecules to come across with the BPO molecules. Figure 7 also shows the decrease of secondary amino groups of HACTP after curing. On the other hand, the exothermal peak at $254^{\circ} \mathrm{C}$ appeared in the DSC plots of Figure 8 was caused by the degradation of reacted HACTP as suggested by TGA. However, the possibility that the opening of HACTP rings took place at that temperature should not be ruled out. $\left(\mathrm{NPCl}_{2}\right)_{3}$ has been reported to polymerize to a transparent rubbery high polymer at $250^{\circ} \mathrm{C}^{18}$

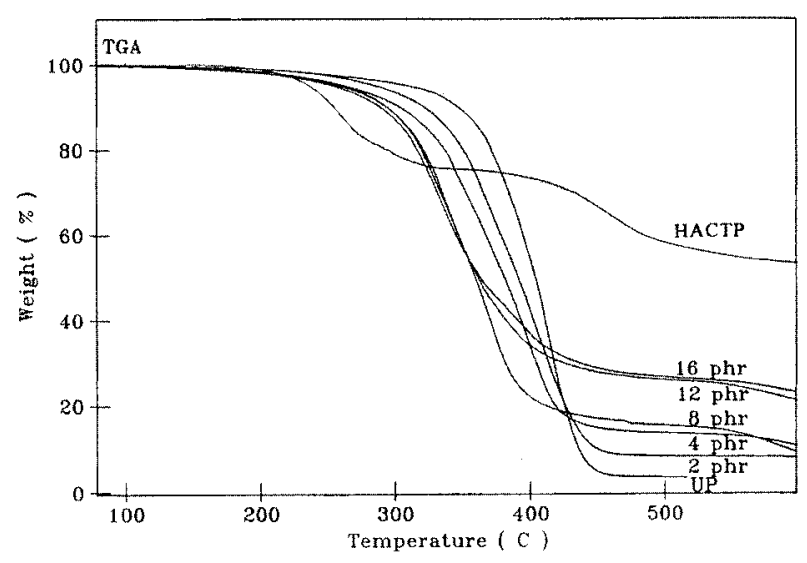

Figure 5 TGA thermograms of HACTP and cured UP resins incorporated with various phr of HACTP. 


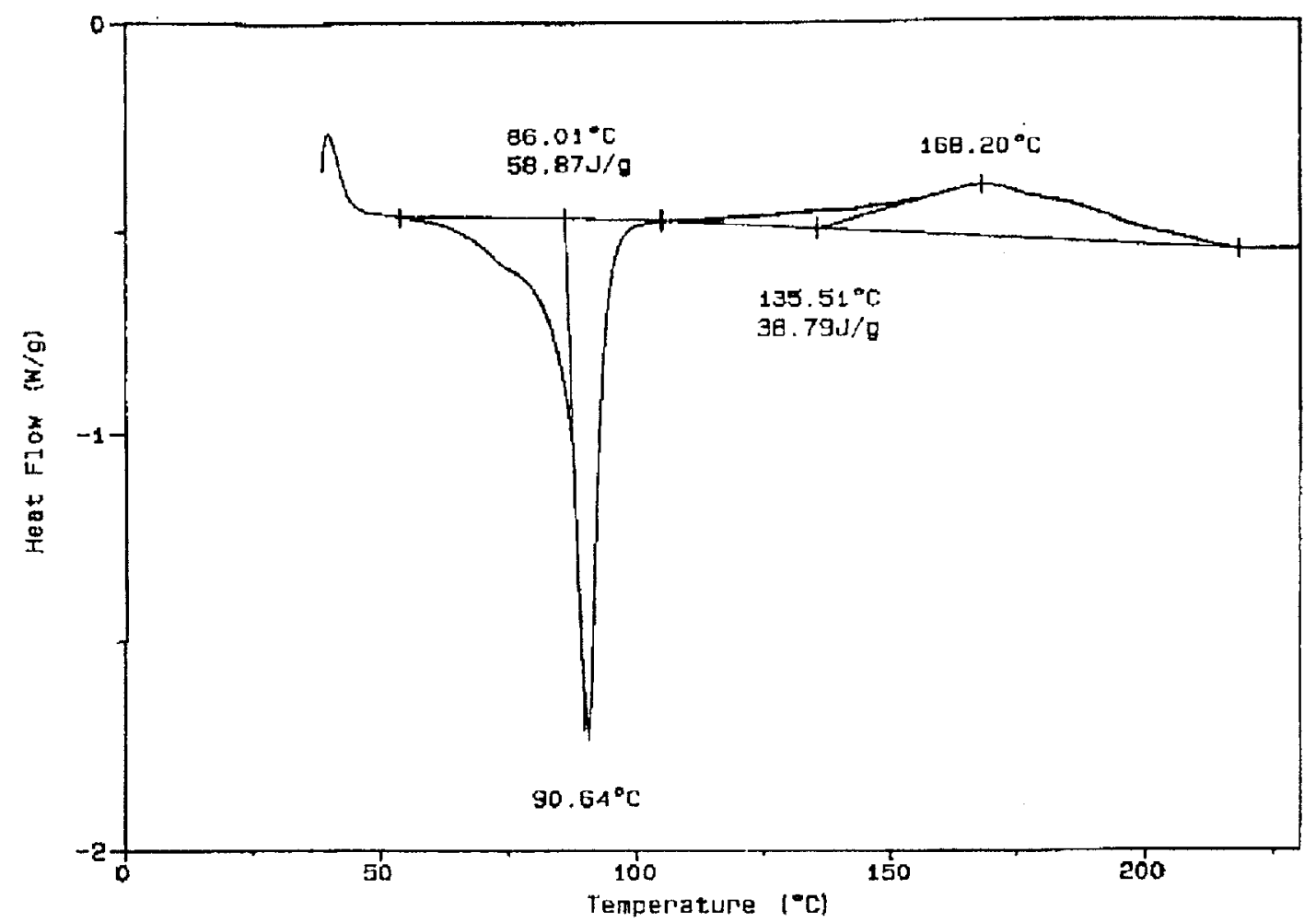

Figure 6 DSC plot of HACTP.
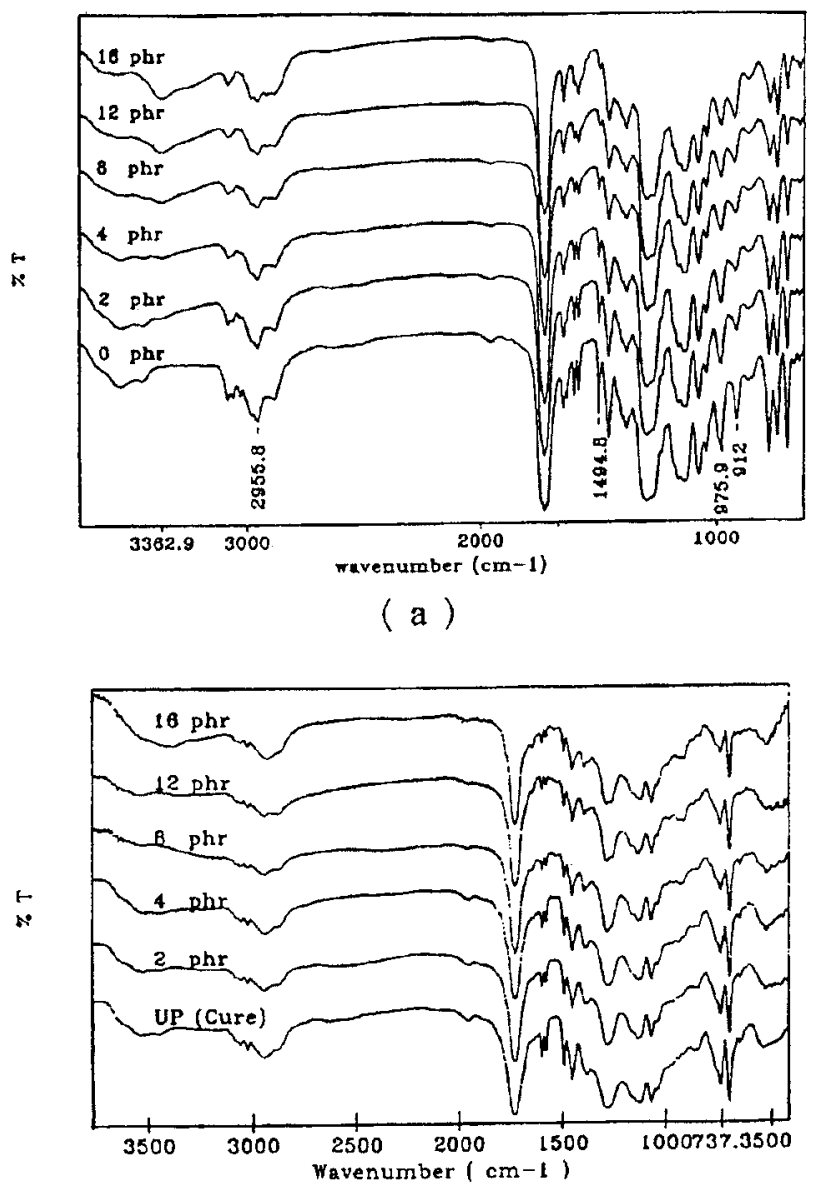

(b)

Figure 7 FTIR spectra of (a) uncured and (b) cured UP resins incorporated with various phr of HACTP.
The degradation temperature of cured UP at $5 \mathrm{wt} \%$ loss was $316^{\circ} \mathrm{C}$ (see Fig. 5), which was gradually decreased to $259^{\circ} \mathrm{C}$ by incorporation of HACTP up to 8 phr. Further increase of HACTP content barely decreased the degradation temperature. On the other hand, the char yield at $500^{\circ} \mathrm{C}$ was increased with the content of HACTP. Although the mechanism of char formation is not clear, the degradation of HACTP was prior to that of the UP resin and its degraded residual has apparently triggered the degradation of UP resins and then interacted with the degraded residual of UP resins to form the char. Figure 9 shows that the oxygen index of UP resins was increased from 20.5 to 25.2, rating from the flammable to self-distinguishable scale, when the content of HACTP was increased to 12

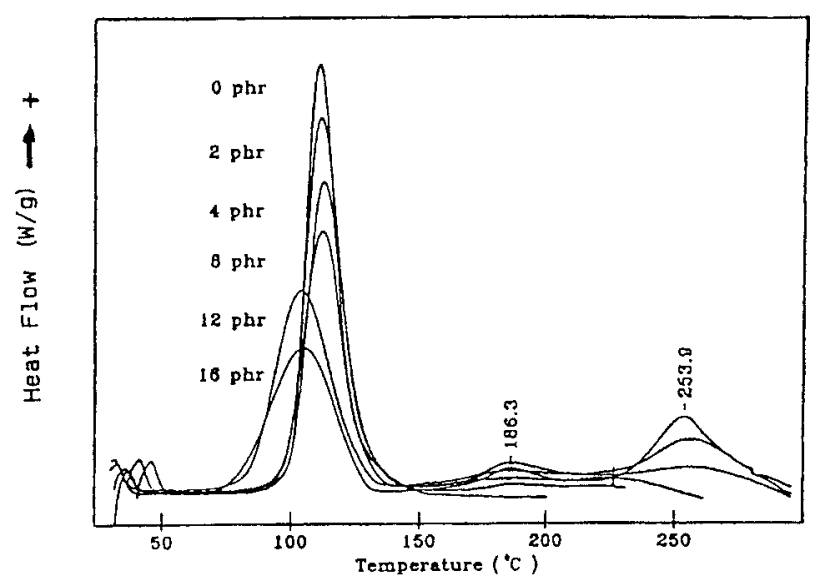

Figure 8 DSC plots of UP resins mixed with various phr of HACTP. 


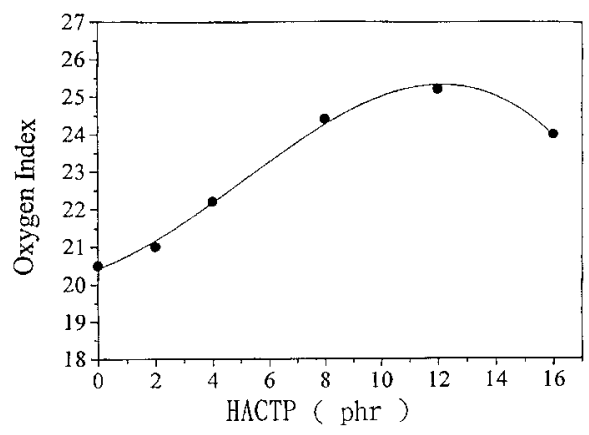

Figure 9 Oxygen index of cured UP/HACTP resins as a function of the HACTP content.

phr. Further increase of HACTP to 16 phr decreased the oxygen index. This might be due to the decreased solubility of HACTP in the UP resins during curing.

\section{CONCLUSIONS}

HACTP was synthesized through the aminolysis of hexa-chloro-cyclotriphosphazene with excess allyamine. It acted as a reactive flame retardant for the UP resins because it could accelerate the curing reaction and increase the oxygen index from 20.5 to 25.2 , rating from the flammable to self-distinguishable scale. Further application of HACTP is under exploration.

\section{References}

1. Rose, H. J. Ann Chem 1834, 11, 131.

2. Allock; H. R.; Kellam, E. C. Macromolecules 2002, 35, 40.

3. Allock, H. R.; Prange, R.; Hartle, T. J. Macromolecules 2001, 34, 5463.

4. Allock, H. R.; Hartle, T. J.; Taylor, J. P.; Sunderland, N. J. Macromolecules 2001, 34, 3896.

5. Brown, D. E.; Ramachandran, K.; Carter, K. R.; Allen, C. W. Macromolecules 2001, 34, 2870.

6. Levchik, G. F.; Grigoriev, Y. V.; Balabanovich, A. I.; Levchik, S. V. Klatt, M. Polym Int 2000, 49, 1095.

7. Rojo, G.; Agullo-Lopez, F.; Carriedo, G. A.; Alonso, F. J. G.; Martinez, J. I. F. Synth Met 2000, 115, 241.

8. Chen-Yang, Y. W.; Hwang, J. J.; Huang, A. Y. Macromolecules 2000, 33, 1237.

9. Allock, H. R. Macromol Symp 1999, 144, 33.

10. Ibim, S. E. M.; Ambrosio, A. M. A.; Kwon, M. S.; El-Amin, S. F.; Allock, H. R.; Laurencin, C. T. Biomaterials 1997, 18, 1565.

11. Cullis, C. F. The Combustion of Organic Polymers; Clarendon: Oxford, 1981.

12. Petreus, O.; Popescu, F. N.; Cascaval, C. N. Angew Makromol Chem 1994, 222, 13.

13. Denq, B. L.; Chiu, W. Y.; Lin, K. F.; Fuh, M. R. S. J Appl Polym Sci 2001, 81, 1161.

14. Denq, B. L.; Chiu, W. Y.; Lin, K. F. J Appl Polym Sci 1997, 66, 1855.

15. Lin, K. F.; Lin, J. S.; Cheng, C. H. J Polym Sci, Polym Chem Ed 1997, 35, 2469.

16. Lin, K. F.; Lin, J. S. J Appl Polym Sci 1993, 50, 1601.

17. Lin, K. F. ; Lin, J. S.; Cheng, C. H. Polymer 1996, 37, 4729.

18. Allock, H. R.; Lampe, F. W. Contemporary Polymer Chemistry, 2nd ed.; Prentice-Hall: Englewood Cliffs, NJ, 1990. 